\title{
Microbial biofilm in the industry
}

\author{
Tatsaporn Todhanakasem
}

Faculty of Biotechnology, Assumption University, Bangkok, Thailand.

Accepted 29 March, 2013

\begin{abstract}
Biofilms represent negative and positive attributes in the industries. Biofilm is a functional consortium of microorganisms attached to either biotic or abiotic surfaces and embedded under the extracellular polymeric substances (EPS). Spoilage and pathogenic microorganisms can develop biofilms on food industrial surfaces that can lead to food spoilage and disease transmission when the inappropriate clean up and control have been applied in the food industies. However, single and mixed species of microbial biofilms also represent tremendous advantages in bioprocesses and waste treatments. Biofilm reactors have been employed in order to improve the productivities, stability of the processes and reduce the production cost. To understand biofilm, numerous direct and indirect experimental approaches have been used to study the biofilms. Molecular genetics approaches have led to study on the process of biofilm development in order to understand its genetic regulations.
\end{abstract}

Key words: Biofilm, advantage, disadvantage, control, industry.

\section{INTRODUCTION}

Biofilm phenomenon is highly found in natural environment in which microorganism prefer to live on any available surfaces rather than living in the form of planktonic cells (free cell) in liquid phase (O'Toole et al., 2000). Microorganism living in biofilm form is more beneficial for cell growth and survival under the protected environment. In addition, biofilm facilitates the accessing to the limited nutrient in the nature. Biofilm can be defined as single species or community of microorganisms that attached to a biotic or abiotic surface and are embedded under extracellular polymeric substances (EPS). Most often, mixed microbial species composed of biofilms are found in natural settings, however, single microbial species do form biofilms on food process equipment and medical equipment. Biofilm of pathogenic microorganisms create the hygienic problem in food industry, medical implants and medical equipments which lead to the disease transmissions (Wong, 1998). In general, microorganisms are thought to initiate biofilm development in response to various environmental signals, such as nutrient availability, temperature, osmolarity, $\mathrm{pH}$, iron and oxygen concentration (O'Toole and Kolter, 1998; O'Toole et al., 2000a, b). Bacteria in biofilms are generally more tolerant to exposure to UV light, display increased rates of genetic exchange, enhance in production of secondary metabolites and promote more efficient biodegradation (Moller et al., 1998). Biofilms represent biological systems with high level of organization where bacteria form structured, coordinated and functional communities.

Microbial biofilm in nature plays a significant role in the production and degradation of organic matter since the bacterial community can have compartmentalized capabilities to carry out many complex metabolic processes within the biofilm communities. Biofilm represents some positive and negative attributes in the industries as discuss in this paper. Therefore, it is necessary to understand biofilm developmental process in detail using the direct, indirect methods and genetic approaches. 


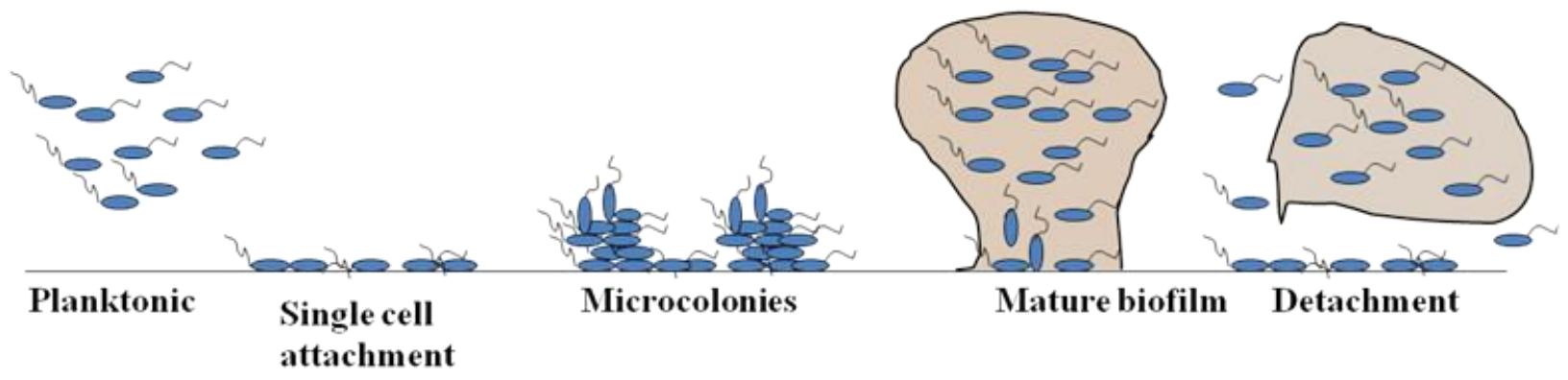

Figure 1. The figure represents the principle biofilm developmental model.

\section{WHAT IS BIOFILM AND HOW DO BIOFILM DEVELOP?}

Pseudomonas aeruginosa has emerged as the most studied single species biofilm model for Gram negative bacteria. Apart from Pseudomonas aeruginosa, Pseudomonas fluorescens, Escherichia coli have also studied in detail (O'Toole et al., 2000) Staphylococcus epidermidis, Staphylococcus aureus and Listeria monocytogenes are among the gram positive bacteria that have been studied lately (Gotz, 2002; Todhanakasem and Young, 2008). These studies provided the principle idea to indicate that biofilm development generally has 4 major stages (Figure 1); 1) individual planktonic cells (free cells) initially attach to a biotic or abiotic surface, 2) formation of microcolonies 3 ) maturation of biofilm quaternary structure and 4) detachment of individual cells that return to the planktonic stage.

\section{Initial attachment}

In the initial attachment, early studies suggested that the overall bacteria surface charge influence on the bacterial colonization (Costerton et al., 1995). However, this idea turned out to be too simplistic because bacterial surfaces are heterogenous and consist of many components including temporary expressed surface polysaccharides and proteins. The expressions of these often changes in response to the environmental signals that induce the biofilm development. The production and activity of cell surface components may be regulated by cell regulatory systems and genetic networks responding to environmental cues. For example, the switch in lipopolysaccharide (LPS) type A and B band in $P$. aeruginosa is influenced by the type of surface material available. This change shifts the bacterium's ability to interact with either a hydrophobic or hydrophilic surface.

In $P$. aeruginosa and most of the biofilm studied microorganisms, flagella and type IV pili play important roles in initial attachment (Burrows et al., 2003). Flagella facilitate the swimming and scanning for an appropriate location for initial contact. Type IV pili play an important role in the movement along the surface and forming group structure by developing the cells piling up on top of each other (O'Toole et al., 2007). E. coli also requires flagellum mediated motility to initiate early attachment and cell spread across a surface (Pratt and Kolter, 1998). Flagella mediated motility also is found to be important to facilitate cell spread out across the surface in Vibrio cholera (Watnick and Kolter, 1999). Thus, it appears that flagella function in many bacteria to promote the initial attachment but may not be required for the downstream development process. Consistent with this conclusion, defective in flagellar and pili function of $V$. cholerae and $E$. coli only caused delay in biofilm formation.

However, beside flagella and pili play important roles in initial attachment, also surface proteins, extracellular proteins and capsular polysaccharide play important role in cell- surface interactions during the initial attachment process. Other outer membrane proteins also reported to be involved in the biofilm development including gene s/p encoding an outer membrane lipoprotein in $E$. coli that was also found to be involved in the initial step of biofilm formation on abiotic surfaces. The alteration of surface protein expression was also found in $E$. coli during the initial attachment step (Otto and Silhavy, 2002).

\section{Microcolony formation}

The step after the cell surface interaction, the microorganisms usually undergo population outgrowth where cell- cell interactions and formation of cell aggregates on the surface accumulation leading to a massive increase in biomass. The surface attached bacteria increase the synthesis of EPS which mainly composes of polysaccharides, proteins (including extracellular enzymes), nucleic acids (DNA, RNA) and other substances. EPS facilitates the bacteria to live effectively in the biofilm mode of growth. The biofilm feature with EPS appears to create a protective environment including increase in antibiotic resistance, increase rates of genetic exchange for evolution, 
increase metabolic activities in the bacterial community and increase secondary metabolite production. EPS also assists to capture the nutrients to feed the cells underneath the biofilm especially under the starvation condition (Angles et al., 1993; Hassett et al., 1999). The EPS is a major component that protects microorganisms against UV, antibacterial agents, disinfectants, heat and drying.

\section{Maturation of the biofilm}

A mature biofilm structure is porous with capillary water channels that allow water, oxygen and nutrient distribution needed for the growth of cells which are embedded under EPS. Therefore, porous structure is a crucial part of biofilm structure and function. EPS is a major component that facilitates the stability of mature biofilm architecture on the substratum. EPS has been reported to (De Beer et al., 1994; Suci et al., 1994) play an important role in the stage of mature biofilm formation as in $P$. aeruginosa and $E$. coli. Different type of microorganisms has different compositions of EPS. Alginate has been implied as a major component of EPS in $P$. aeruginosa. The gene encode for alginate synthesis $(a / g C)$ is induced immediately after the bacteria attach to the surface. There is a report on the link in the down regulation of flagellum synthesis and the up-regulation of alginate synthesis in $P$. aeruginosa (Gacesa, 1998; Watnick et al., 1999). However, the evidence of the regulation between flagella and alginate is reasonable since when bacterial cells adjust to an immobile life on a surface, the probably lose their flagella and increase the production of EPS that requires alginate as a major component when they form the mature biofilm.

Communication signals like a quorum sensing additionally play a major role in controlling biofilm maturation stage. In $P$. aeruginosa, quorum sensing molecules derived acylhomoserine lactones (acyl-HSLs) are required for biofilm maturation (Davies et al., 1998; Stickler et al., 1998). A mutation in gene encodes for the synthesis of acylhomoserine lactones was captured in the early cell surface interaction without the development of the mature biofilm architecture. The signal is believed to be function as bacterial communication for the bacterial attachment and group together. However, the signal also plays a role in bacterial contact inhibition once cell attachments are more crowded. The quorum sensing inhibitor compounds were found to inhibit the mature biofilm formation since they interrupted cell to cell communication signals (Davies et al., 1998).

\section{Detachment}

Biological and physical phenomena are believed to be involved in the detachment process. The bacterial growth rate and substrate utilization are found to control detachment frequency especially under the starvation of the old mature biofilm. The low efficiency of mass transfer to the bacteria deep inside the old mature biofilm causes the selective detachment. As in $P$. aeruginosa, the formation of pore, channel and dispersion were found during the detachment stage (Sauer et al., 2002). The detachment process was believed to occur in order to maintain the internal porosity within the biofilm to increase the overall mass transfer to feed the bacteria inside the biofilm. The biological mechanism of the bacterial cell that facilitates detachment such as the enzyme alginate lyase was reported but there are likely to be other factors. Nonetheless, the overexpression of alginate lyase could speed up the detachment process of the mature biofilm in $P$. aeruginosa (Boyd and Chakrabarty, 1994). Streptococcus mutans has its own protease that cleaves its own surface proteins which would serve as a mechanism to release the bacteria from the biofilm (Lee et al., 1996). In $P$. aeruginosa, flagella seem to play an important role in detachment process. A high amount of motile bacterial cells was observed during the dispersion (Sauer et al., 2002). In physical terms, the detachment of biofilm partly can occur when external forces exceed the internal strength especially when the biofilm thickness is increased over the time. The increased in biofilm thickness can reduce the stability in biofilm structure exposing it to shear forces.

\section{DELETERIOUS EFFECTS OF BIOFILM IN THE INDUSTRY}

Microbial colonization and embedded under extracellular polymeric substance (EPS) called biofilm has been widely found in the food industry. Biofilm formation can be found in all type of microbes which can lead to serious hygiene problems, economical losses due to the food spoilage and equipment impairment. The biofilm is probably forms by single species or mixed species of microbes. If the biofilm forms by spoilage or pathogenic microorganisms in the food industry, it will create serious problems which can cause the cross contamination to the food (Wong, 1998). Outbreaks of pathogens associated with biofilms have been related to the presence of Listeria monocytogenes, Yersinia enterocolitica, Campylobacter jejuni, Salmonella spp., Staphylococcus spp. and Escherichia coli O157:H7 (Somers and Wong, 2004; Lapidot et al., 2006). Microorganisms in biofilms are also able to catalyze chemical and biological reactions causing metal corrosion, reduce heat transfer efficiency of heat exchangers and pipelines. Biofilm formation in the pipe reduces the liquid flow rate, heat transmission efficiency and pipe corrosion in terms of acid production from the bacterial consortium in the biofilm. Biofilm commonly contaminate industrial pipelines, food contact surfaces, floors when the inappropriate sanitizing has been applied in the industrial cleaning up since the biofilm can develop on various kinds of surface materials 
Day 1

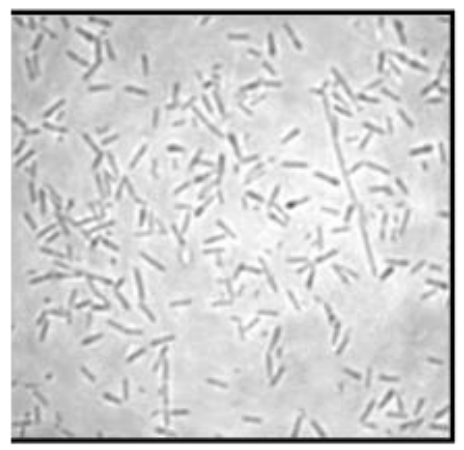

Day 2

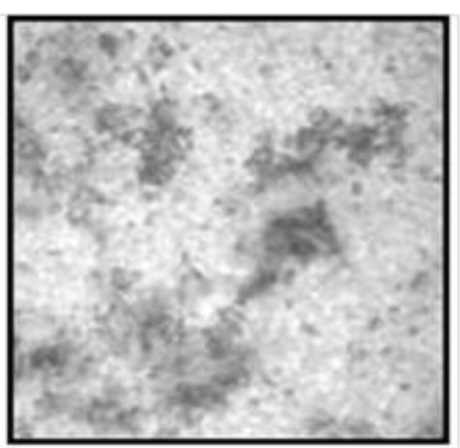

Day 3

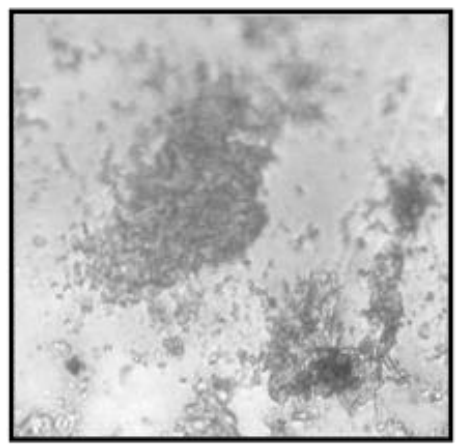

Figure 2. The figure represents biofilm development $S$. typhimurium on the polyvinyl chloride coupon under the bright-field microscope and the surface attached cells were captured at the magnification of 400x.

such as rubber, plastic, aluminium and stainless steel etc (Chae and Schraft, 2000). Biofilm formation also tends to increase with the hydrophobicity of the surface materials rather than hydrophilic materials. In the dead zone like crack, corner, joint and gasket are places where the remaining of the biofilm are probably found after the inappropriate cleaning. The protective environment of the mature biofilm in which the EPS is massively developed leads to the more tolerant to many stresses including the disinfectants or sanitizers than the free floating cells or planktonic cells (Gilbert et al., 2001).

The biofilm formations of foodborne pathogens can cause the disease transmission especially in the detachment stage. Meat, dairy and poultry industries are the principal reservoirs of Salmonella, Campylobacter, Listeria, Yersinia enterocolitica and Staphylococcus aureus worldwide that mediate the disease transmission to the consumers when the products are inappropriately cooked (Farber and Peterkin, 1991; Dewanti and Wong, 1995; Kim et al., 2008). However, the formation of biofilm in the industry can take from several days to weeks therefore, the effective cleaning methods should be applied at the first place before the mature biofilm is developed as the older the biofilm age, the harder to be eliminated. Figure 2 represents the biofilm development of Salmonella typhimurium on polyvinyl chloride as a representative for hydrophobic surface after 3 days inoculation time. On day 1 , the individual cells started to attach on the surface in which EPS started to develop on day 2. Once EPS develops, the biofilm was hardly to be eliminated by sanitizing agents (Todhanakasem, 2010).

\section{BIOFILM CONTROL STRATEGY}

Since biofilms create problems in various food industrial sectors such as brewing, dairy processing, fresh produce, poultry processing and red meat processing, thus many biofilm control strategies have been risen up. Biofilm mode of life leads to increased resistance to antimicrobial compounds which has made the elimination from food processing facility becomes more challenge. In order to provide the effective control of undesirable biofilm, the understanding of the type of microbial biofilm need to be known before performing the sanitation process. The formation of biofilm can be prior avoided by choosing the correct materials and performing the appropriate cleaning methods at the first place. Also, the equipment design should not contain any fault exist sanitation like dead spaces, crevices, corners, cracks, gaskets, valves and joints which are vulnerable area for biofilm accumulation.

In the elimination of bioiflm, the combinations of physical and chemical methods need to be applied in the cleaning up process. The physical methods that have been applied include super high magnetic fields, mechanical grinding, ultrasound treatment, high pulsed electrical fields, brushing with high pressure (Okuno, 1993; Pothakamury, 1996; Qian, 1997). Brushing with high pressure with stream is one of the effective methods. Chemical such as chlorine, lauricidin, hydrogen peroxide, chlorinated alkaline detergent, peracetic acid and iodine have been widely used for the industrial clean up (Carpentier and Cerf, 1993). However, the disinfectant resistances are found to be directly proportional to the thickness of 3-dimensional structure of biofilm and the resistance is lost as soon as the biofilm structure is disrupted (Cerf, 1993). The inappropriate concentration of the disinfectants or ineffective cleaning are also found to develop more resistant of the biofilm against the cleaning agents (Hood, 1995). The physical treatment prior the chemical treatment has been found to be the most effective since the detachment of the biofilm from the physical treatment make it more sensitive to the disinfectants or antimicrobial compounds. Generally, disinfectants do not penetrate the biofilm matrix. Therefore, cleaning is the first step and the most 
important step to improve the sanitation of the processing equipment. Recently, biological treatment like the utilization of enzyme has been emerged as an alternative cleaning method as green chemicals. Enzymes have been used to hydrolyze EPS matrix (Potthoff, 1997). As EPS composes of heterogeneity of compounds, therefore the specific type or mixture of enzymes may be required in order to provide the effective cleaning. The combination of proteolytic enzymes with surfactants was found to enhance the efficiency of cleaning on Bacillus spp. Biofilms (Parkar et al., 2004). Biosurfactants produced from the microbes were also found to impair biofilm forming abilities. Biosurfactants produced by Lactococcus lactis impaired biofilm formation on silicone rubber (Rodrigues et al., 2004). Surfactin from Bacillus subtilis was found to disrupt biofilm without affecting cell growth and prevent biofilm formation of Salmonella enteric and E. coli (Mireles et al., 2001). Microbial molecules like nisin, reuterin and pediocin have been reported on their abilities to control biofilm formation by $L$. monocytogenes (Dufour et al., 2004). However, the use of biological control is not a cost effective method in comparison to the chemical used. As chemical disinfectants have been widely used to eliminate biofilms, the properties of the chemical have been concerned based on effectiveness, safety, easily apply, easily rinsed off from surfaces, leaving no toxic residues that can affect the health properties and sensory values of the final products. In the past, efficiencies of biological and chemical disinfectants were previously tested on planktonic (free cell) rather than biofilm mode of growth. Biofilms have been reported to be 100-1000 times resistant to disinfectants (Gilbert et al., 2002). Thus, in order to identify the efficiency of disinfectant in the elimination of biofilm must be evaluated in the biofilm mode of growth. The new prospective control has been focused on the use of quorum sensing inhibitory compound as it has been known that quorum sensing is essential for mature biofilm formation. Thus quorum sensing inhibitory compounds may represent a significant impact on biofilm formation (Dong et al., 2002).

Biofilm prevention should be performed together with biofilm elimination. The main strategy to prevent biofilm is to clean and disinfect regularly before bacteria attach firmly to surfaces. The cleaning in the short time interval would be highly recommended as the most effective method to eliminate the biofilm since the elimination would be performed at the earlier stage of the biofilm development in which the EPS is less and disinfectant is accessible to kill the microbes underneath the biofilm. Other attempts are to identify materials that do not promote or even suppress biofilm formation. The coating, painting walls, ceiling and floor with antimicrobial agents have been applied. The impregnation of surface material with biocides or antimicrobials also plays an important role in minimizing the bacterial colonization or modifying the surface physicochemical properties (Rogers et al.,
1995; Rosmaninho, 2007). Coating surfaces with silver also found to inhibit biofilm formations (Klueh et al., 2000). Non-ionic and anionic surfactants were evaluated to prevent the bacterial adhesion on stainless steel and glass surfaces which gave more than $90 \%$ inhibition of adhesion ((Meylheuc et al., 2006).

\section{ADVANTAGES OF BIOFILM IN THE INDUSTRY}

Biofilms represent great benefits in biotechnology industries because of their self- immobilization with high concentration of biomass within EPS that provide the high resistance to toxic compounds, long term activity which all facilitate continuous process with the high stability. Biofilm reactor can be set as continuous reactor operated with more cost effectiveness than batch process of free cell because of the reduction in reactor preparation, cell growth and product recovery. Biofilm reactors represent the significant advantage where in the reactor capacity obtained by using free cells is limited by biomass concentration. Therefore, biofilm reactor has been considered to be used in the industry for various economic reasons. Biofilms of bacteria, fungi and their enzyme products can act as biocatalysts to provide high specificity productions under the mild condition. Various biofilm processes have been implemented commercially with the great success over the last few decades (Qureshi et al., 2005). Biofilms have been used in the food sector in the productions of various value added product organic acid (acetic acid, lactic acid, succinic acid and fumaric acid), polysaccharide, ethanol, butanol.

Many microorganisms are capable to develop single species biofilm that are applicable for bioprocess. Mostly the biofilm can be form spontaneously under suitable condition specific for each microbe. Biofilm growth in a multi-stage process involving initial cell attachment to a solid surface and follow by surface adhesion by selfproduced EPS. Surface properties play an important role in the cell attachment (Goller and Romeo, 2008). The primary method used for cell immobilization is organism entrapment within polymers such as calcium alginate, $\kappa$ carrageenan and membrane. Recently, self-immobilized cells and cells that grow as aggregates without the addition of any polymers or cross- linking chemical have been used as biofilm reactors. Biofilm in the fermentation processes can be maintained in the reactor as biofilm reactor in which the cell recycle can be processed without the need for re-inoculation of the culture. The reactors can be manipulated in variety of configurations including batch, repeated batch, continuous stirred tank, fluidized bed, airlift. In order to use biofilm reactor, it is necessary to identify whether the desirable microorganism using in the process can develop biofilm on the supporter otherwise, biofilm reactor cannot be applied for the bioconversion. Mostly single species biofilm has been widely used in the production (Qureshi et al., 2005). 
Biofilm reactors have not yet been used commercially for the production of value added compounds even though of laboratory scale studies have been conducted lately (Qureshi et al., 2005). Biofilm reactors have been applied for the conversion of agricultural materials such as starch, sugars and glycerol to various alcohol such as ethanol, butanol, 2,3- butanediol) or even organic acids such as acetic acid, fumaric acid and citric acid). Zymomonas mobilis biofilm has been efficiently used for ethanol production in polypropylene packed bed reactor in which the production rate was $536 \mathrm{gL}^{-1} \mathrm{~h}^{-1}$ while $5 \mathrm{gL}^{-1} \mathrm{~h}^{-1}$ was obtained from continuous free cell culture (Kunduru and Pometto, 1996). Acetic acid bacterial biofilm was grown on beechwood shaving that was used to convert ethanol to vinegar to produce final acetic acid concentration of $120 \mathrm{gL}^{-1}$ had been obtained through the biofilm packed bed process (Qureshi et al., 2005). Biofilm packed bed reactor of Lactococcus lactis on cotton fabric was applied to produce nisin (Liu, 2005). Biofilm processes involving toxic compounds in the substrate have been recently focused, $Z$. mobilis biofilm was found to be tolerated to toxic substrate benzaldehyde than free cells in continuous biofilm reactor ( $\mathrm{Li}$ et al., 2006). The fluidized bed biofilm reactor (FBBR) have been effectively used more than two decades for treating industrial wastewater in which the biofilm was found to be more resistant to the toxic chemical in the waste than free cells (LaPara et al., 2001).

Even though, biofilm reactors have been shown to be effectively produced desirable products with the high productivities, the barriers of using biofilm reactors also be found. The excessive sloughing of EPS can lead to the difficulties for downstream processing and product purification. The excessive growth of cell with the thick layer of biofilm can cause the blockage of the process in which the mixing is not optimized and leads to the reduction of the reactor efficiency. Inside the mature biofilm, the variation in the physiological state and limitation results in the concentration gradients of substrate uptake and waste compounds within biofilm (Stewart and Franklin, 2008). The thick layer of the biofilm also creates the limitation in substrate and oxygen diffusions mostly to the inner most of the microbes living in the biofilm layer (Stewart, 2003). Thus substrate uptake and utilization as well as product purity and recovery might be affected with consequently effects on the productivity and yield of biofilm processes. In the aerobic wastewater system the dissolve oxygen amount must be sufficiently supplied to feed the culture in the inner part of the biofilm layer when the mature biofilm is developed in order to maintain the process efficiency (Nicolella et al., 2000). Apart from the oxygen and substrate that hardly diffuse to feed the microbes in the inner part of the biofilm, the product itself also does not efficiently diffuse out of the thick biofilm layer in which the product toxicity probably occur to kill the cells underneath the biofilm and limit the production. Therefore, the appropriate reactor design can be used to control the biomass accumulation and improve the mass transfer efficiency such as fluidized bed reactor (Qureshi et al., 2005). Quorum sensing affects various aspect of biofilm developmental process including its dispersion. Other factors such as shear forces, nutrient availability and cell density have been suggest as triggering factors for biofilm dispersion (Spormann, 2008). If these mechanisms are clearly understood, the control process to inhibit the excessive biofilm development which impedes the bioprocess efficiency might be able to process in order to enhance the productivity and facilitate the industrial clean up. The variation in the biofilm dynamic life cycle also has been found to be a cause of the fluctuation in the amount of active biomass within the reactor thus it affects the productivity. Despite the minor negative effects of the biofilm reactor, many previous works have been shown that biofilm reactor still provides the higher productivity than the free cell reactor or suspended cell reactors.

\section{TECHNICAL APPROACHES TO STUDY BIOFILM FORMATION}

The preliminary requirement to understand, prevent, regulate and control of biofilm in the industry is to monitor the biofilm developmental process in either qualitative or quantitative determinations. There are various indirect and direct methods that have been used to study biofilm formation. Many indirect methods can be employed to study on the biofilm formation on food contact surfaces on sites such as swabbing, rinsing and agar contact methods and quantitatively studied on the number of adherent bacterial cells. This approach has been further done by standard plate counting. This conventional plating is a labour intensive method and slow (Donlan and Costerton, 2002). Biofilm forming abilities of many microbes were tested on variety of surfaces using coupons including glass, plastic and stainless steel and plate counting. However, many microorganisms in the biofilm are possibly subjected to the stress which renders the microbes to be non-culturable (Chae and Schraft, 2000). Therefore, the inaccurate data is probably obtained with this method.

The microscopic method especially scanning electron microscopy was commonly used to observe the biofilm in the past. Recently, environmental scanning electron microscopy in which the sample can be visualized without the needed of dehydration, fixation and staining has been emerged to study on the biofilm formation in the food contact surface. However, the obstacle is arisen on the study of biofilm around the dead zone where it is hard to get access (Leriche, 1995). Microscopy techniques have been used as a way to directly visualize biofilm development. Fluorescence microscopy, scanning electron microscopy (SEM), brightfield microscopy and confocal laser scanning microscopy have been widely 


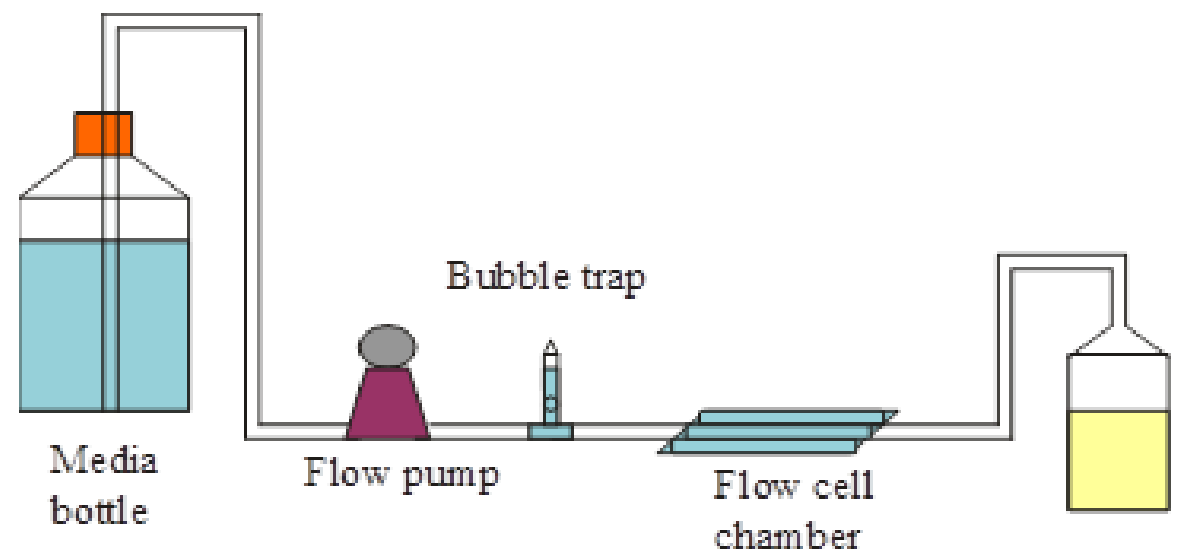

Figure 3. The dynamic flow cell system. Flow cells are composed of parallel multiple channels which allow cells to grow under continuous feeding of fresh media from the media bottle and the effluent from the flow cell chamber is collected in effluent bottle. The bubble traps is used to eliminate out all bubbles that will disrupt the biofilm formation in the flow cell chamber.

used to study biofilm structure and to define the steps of biofilm development (Chae and Schraft, 2000). Mostly in the past, the microscopy procedures have given limited insight when the specimens need to be stained or chemically treated before observing samples (Marsh et al., 2003). These procedures cause the real structure of biofilm structure to be distorted. Therefore, the idea of continuous nondestructive monitoring of biofilm process was risen up in which this technique is applicable to monitor the biofilm sample in the aqueous system without the requirement for the sample removal and monitoring the biofilm in the real time. With the technique, it should be noninvasive and minimize interferences from microorganisms in the bulk phase. The combination of microscopic study and flow cell system has been risen up to overcome these problems. This system provides the condition to study on the fully hydrated biofilm architecture at a real-time system in which mimics the natural environment (Figure 3) (Heydorn and Zottola, 2000). The system facilitates biofilm study without interruption during the experimental period which can be days to weeks. The system contains a vessel with influx and effluent ports through which fresh growth medium is continuously pumped under the laminar flow condition. The bacterial culture is inoculated into the flow cell and after a certain time, fresh sterile medium is pumped through the vessels and the biofilm is allowed to develop over a time. This system closely mimics the conditions under which bacterial biofilms form in some natural environment. The flow cell system is normally mounted on any type of microscope where you can observe the biofilm development without disturbing the culture system along the processing time. If the system is mounted with confocal laser scanned microscopy, then the biofilm three dimensional structures can be observed.
Spectrochemical techniques based on light intensity from absorbed, scattered and/ or emitted in depending on the amount of biofilm or biomass have been utilized for quantitative assay of biofilm. The analysis has been done by variety of radiation signals including gramma-ray, $X$ rays, ultraviolet, infrared and fluorescence or even naturally produced bioluminescence (Stewart and Williams, 1992). Bioluminescence of Vibrio harveyi biofilm in the flow cell system was used to facilitate the evaluation on the toxicity of antifouling coating on the biofilm forming ability (Arrage, 1995). The attachment of Eschericia coli $\mathrm{K} 12$ was also evaluated by having lux gene reporter plasmid transferred to $E$. coli and the attachment rate was referred to the intensity of light (Denyer et al., 1991).

Electrochemical techniques using electrode as probe typically less than $20 \mu \mathrm{m}$ tip diameter to monitor cell metabolisms based on the concentration of chemicals including oxygen, $\mathrm{pH}$, glucose as general references. Microelectrodes respond to interferences and signal drift by submerging the probe into the biofilm system that need to be analyzed. For example, the used of microelectrodes to probe the metabolic activities within the biofilm of Bacillus laevolacticus (de Boer et al., 1993). However, a single analytical technique is hardly to explain the whole system of biofilm formation.

Over the past decades, biofilm quantification in microtiter plates have been described to determine the amount of the bacterial attachment which provides an assessment of surface attach biomass (Djordjevic et al., 2002). This is a highly effective method to study the bacterial attachment rate with the high throughput outcomes. Many assays have been designed to serve various purposes including crystal violet (CV) assay, Syto9 assay, resazurin assay, fluorescein diacetate 


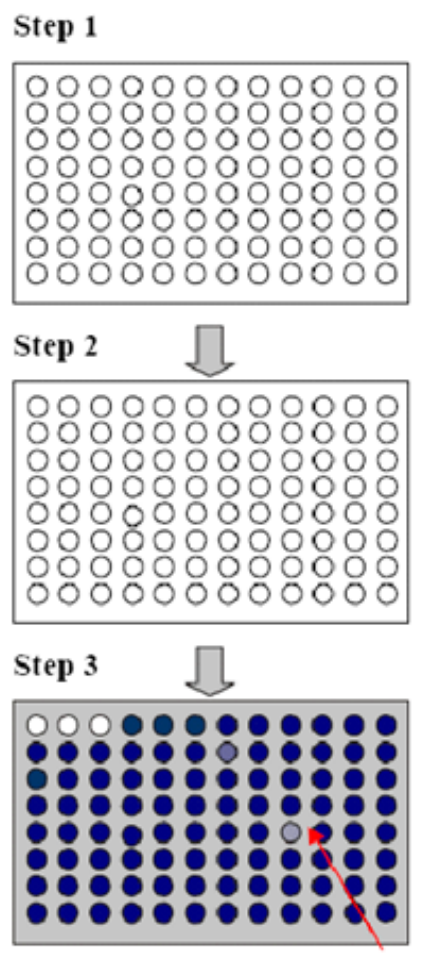

Individual cells from the library mutants (from transposon

mutagenesis) are inoculated into each well on 96 wells plate

Cultures are transferred to PVC 96 wells plate

Attached bacteria were stained with crystal violet or other

detectable dyes. The extracted dye stained on attached cells in

each well was quantified using microtiter plate reader. The OD

value corresponds to the amount of the bacterial attachment. The

low intensity represents the defective in the biofilm formation or

lower number of bacterial attachment.

Figure 4. The figure represents the microtiter plate assay for the selection of gene that is essential for biofilm formation under the static condition.

(FDA) assay, XTT and dimethyl methylene blue (DMMB) assay. The assay can be classified into biofilm biomass assay (quantification on biofilm matrix, live and dead cells), viability assay (quantification on viable cells only) and matrix quantification assay (quantification on biofilm matrix only). These assays could be broadly applied to many microbial biofilms. Crystal violet dye can bind to negatively charged microbial surface molecules and EPS (Li et al., 2003; Stepanovic et al., 2004). DNA of live and dead cells can be stained with Syto9 (Boulos et al. 1999). In order to distinguish between live and dead cell the quantification based on the cell metabolic activity need to be performed including resazurin, fluorescein diacetate (FDA), XXT and dimethyl methylene blue (DMMB). Resazurin assay can be done based on the metabolic activity of the cell (O'Brien et al., 2000). The active cells or live cells represent their capability to convert the non detectable signal to detectable signal in which some of the dye can be converted to fluorescence by the active cells or live cell. The signal can be quantified by measuring the absorbance using spectrophotometer.

\section{GENETIC APPROACH TO STUDY BIOFILM}

Many studies have been done to identify bacterial elements, genetic determinants and regulatory system that are necessary for biofilm development in order to understand the biofilm development in a whole. Genetic elements are required to control the bacterial transition through the developmental pathway in response to environmental cues. Simple genetic screens have been used by a number of groups (Genevaux et al., 1996; O'Toole and Kolter, 1998). Transposon mutagenesis to generate mutants has been widely applied to study on the gene related to biofilm formation of the studied microbes. The microtiter plate made from polypropylene, polycarbonate plastic or borosilicate glass to serve as a substratum for biofilm formation under the static condition has been a high throughput technique for this approach (Pittsa, 2003). However, the microtiter plate made of polyvinylchloride (PVC) is the most commonly used. The microscopic observation of PVC plate substratum shows initial attachment of monolayer cells, subsequent microcolonies formation, mature biofilm and detachment (O'Toole et al., 2000). Biofilm development in a microtiter plate can be visualized by staining the attached cells (crystal violet or other dyes as indicated in the above section). The biofilm formation can be quantified by measuring the absorbance of the dye with a spectrophotometer. In addition to the biofilm development study in microtiter plate, the 96 well microtiter plate has also been used as high throughput screens of many thousand randomly generated mutants that usually are 
created by transposon mutagenesis (Figure 4). The mutation at the gene essential for the bacterial attachment causes the deficiency in the bacterial attachment on the surface which develops the low intensity staining of dye and the gene can be identified based on molecular technique.

\section{Conclusion}

Based on the earlier studies, biofilm formation can be considered as a well regulated developmental process that leads to the formation of complex cell communities in response to the environmental signals. Biofilm formation is still be a broad and complex phenotype. Many biofilm traits have been developed differently in response to different environmental cues in which control by genetic networks. Therefore, there is no mechanistic basis on any one particular biofilm trait to make a conclusion on biofilm developmental phenomena as a whole. Biofilm represents its benefits and deleterious effects in the industries. Understanding the biofilm developmental process probably paves the way to eliminate spoilage or foodborne pathogenic biofilm from food industries or facilitate the useful microbial biofilm to efficiently develop in biofilm reactors in order to improve the productivity in bioprocess.

\section{REFERENCES}

Angles ML, Marshall K, Goodman AE (1993). Plasmid transfer between marine bacteria in the aqueous phase and biofilms in reactor microcosms. Appl. Environ. Microbiol. 59(3):843-850.

Arrage AA, Vasishtha VA, Sundberg D, Baush G, Vincent HL, White DC (1995). Online monitoring of biofilm biomass and activity on antifouling and fouling- release surfaces using bioluminescence and fluorescence measurements in a controlled laminar-flow field. J. Ind. Microbiol. 15:277-282.

Boulos L, Prevost M, Barbeau B, Coallier J, Desjardins R (1999). LIVE/DEAD BacLight : application of a new rapid staining method for direct enumeration of viable and total bacteria in drinking water. $\mathrm{J}$. Microbiol. Methods 37(1):77-86.

Boyd A, Chakrabarty AM (1994). Role of alginate lyase in cell detachment of Pseudomonas aeruginosa. Appl. Environ. Microbiol. 60(7):2355-2359.

Burrows LL (2012). Pseudomonas aeruginosa twitching motility: Type IV Pili in Action. Annu Rev Microbiol. Carpentier B. and Cerf O. (1993). Biofilms and their consequences, with particular reference to hygiene in the food industry. J. Appl. Bacteriol. 75(6):499-511.

Chae MS, Schraft H (2000). Comparative evaluation of adhesion and biofilm formation of different Listeria monocytogenes strains. Int. J. Food Microbiol. 62(1-2):103-111.

Costerton W, Lewandowski Z, Caldwell DE, Korber DR, Lappin-Scott HM (1995). Microbial biofilms. Annu. Rev. Microbiol 49:711-745.

Davies DG, Parsek MR, Pearson JP, Iglewski BH, Costerton JW, Greenberg EP (1998). The involvement of cell-to-cell signals in the development of a bacterial biofilm. Science 280(5361):295-298.

De Beer D, Srinivasan R, Stewart PS (1994). Direct measurement of chlorine penetration into biofilms during disinfection. Appl. Environ. Microbiol. 60(12):4339-4344.

de Boer JP, Cronenberg CC., de Beer D, van den Heuvel JC, de Mattos MJ, Neijssel OM (1993). pH and Glucose Profiles in Aggregates of Bacillus laevolacticus. Appl. Environ. Microbiol. 59(8):2474-2478.

Denyer SP, Jassim SAA., Stewart GSAB (1991). In vivo bioluminescencefor studying the adhesion of bacteria. Biofouling 5 :
125-132

Dewanti R, Wong AC (1995). Influence of culture conditions on biofilm formation by Escherichia coli O157:H7. Int. J. Food Microbiol. 26(2):147-164.

Djordjevic D, Wiedmann M, McLandsborough LA (2002). Microtiter plate assay for assessment of Listeria monocytogenes biofilm formation. Appl. Environ. Microbiol. 68(6):2950-2958.

Dong YH, Andi R, Gusti QZ, Jin-Ling X, Lian-Hui Z (2002). Identification of quorum-quenching $\mathrm{N}$-acyl homoserine lactonases from Bacillus species." Appl. Environ. Microbiol. 68(4):1754-1759.

Donlan RM, Costerton JW (2002). Biofilms: survival mechanisms of clinically relevant microorganisms. Clin. Microbiol. Rev. 15(2):167193.

Dufour MS, Robin S, Bremer PJ (2004). Development of a laboratory scale clean-in-place system to test the effectiveness of natural antimicrobials against dairy biofilms. J. Food Prot. 67(7):1438-1443.

Farber JM, Peterkin PI (1991). Listeria monocytogenes, a food-borne pathogen. Microbiol. Rev. 55(3):476-511.

Gacesa P (1998). Bacterial alginate biosynthesis--recent progress and future prospects. Microbiology 144(5):1133-1143.

Genevaux P, Muller S, Bauda P (1996). A rapid screening procedure to identify mini-Tn10 insertion mutants of Escherichia coli K-12 with altered adhesion properties. FEMS Microbiol Lett 142(1):27-30.

Gilbert P, Allison DG, McBain AJ (2002). Biofilms in vitro and in vivo: do singular mechanisms imply cross-resistance? J. Appl. Microbiol. 92Suppl: 98S-110S.

Gilbert P, Das JR, Jones MV, Allison DG (2001). Assessment of resistance towards biocides following the attachment of microorganisms to, and growth on, surfaces. J. Appl. Microbiol. 91(2):248254.

Goller CC, Romeo T (2008). Environmental influences on biofilm development. Curr. Top Microbiol. Immunol. 322:37-66.

Gotz F (2002). Staphylococcus and biofilms. Mol. Microbiol. 43(6):13671378.

Hassett DJ, Ma JF, Elkins JG, McDermott TR., Ochsner UA., West SE, Huang CT, Fredericks J, Burnett S, Stewart PS, McFeters G, Passador L, Iglewski BH (1999). Quorum sensing in Pseudomonas aeruginosa controls expression of catalase and superoxide dismutase genes and mediates biofilm susceptibility to hydrogen peroxide. Mol. Microbiol. 34(5):1082-1093.

Heydorn AEB, Hentzer M, Parsek MR, Givskov M, Molin S (2000). Experimental reproducibility in flow-chamber biofilms. Microbiology 146:2409-2415.

Hood SK, Zottola EA (1995). Biofilm in food processing. Food Control 6:9-18.

Kim TJ, Young BM, Young GM (2008). Effect of flagellar mutations on Yersinia enterocolitica biofilm formation. Appl. Environ. Microbiol. 74(17):5466-5474.

Klausen M, Heydorn A, Ragas P, Lambertsen L, Aaes-Jørgensen A, Molin S, Tolker, Nielsen T (2003). Biofilm formation by Pseudomonas aeruginosa wild type, flagella and type IV pili mutants. Mol. Microbiol. 48(6):1511-1524.

Klueh U, Wagner V, Kelly S, Johnson A, Bryers JD (2000). Efficacy of silver coated fabric to prevent bacterial colonization and subsequent device-based biofilm formation. J. Biomed. Mater. Res. 53(6):621631.

Kunduru MR, Pometto ALIII (1996). Continuous ethanol production by Zymomonas mobilis and Saccharomyces cerevisiae in biofilm reactors. J. Ind. Microbiol. 16(4):249-256.

Lapara TM, Konopka A, Nakatsu CH, Alleman JE (2001). Thermophilic aerobic treatment of a synthetic wastewater in a membrane-coupled bioreactor. J. Ind. Microbiol. Biotechnol. 26(4):203-209.

Lapidot A, Romling U, Yaron S (2006). Biofilm formation and the survival of Salmonella typhimurium on parsley. Int. J. Food Microbiol. 109(3):229-233.

Lee SF, Li YH, Bowden GH (1996). Detachment of Streptococcus mutans biofilm cells by an endogenous enzymatic activity. Infect Immun 64(3):1035-1038.

Lemon KP, Higgins DE., Kolter R (2007). Flagellar motility is critical for Listeria monocytogenes biofilm formation. J. Bacteriol. 189(12):44184424.

Leriche V, Carpentier B (1995). Viable but nonculturable Salmonella 
typhimurium in single and binary species biofilms in response to chlorine treatment. J. Food Prot. 58:1186-1191.

Li X, Zuan Y, Jianping X (2003). Quantitative variation of biofilms among strains in natural populations of Candida albicans. Microbiology 149(Pt 2):353-362.

Li XZ, Jeremy SW, Staffan K, Bettina R (2006). Enhanced benzaldehyde tolerance in Zymomonas mobilis biofilms and the potential of biofilm applications in fine-chemical production. Appl Environ. Microbiol. 72(2):1639-1644.

Liu XEA (2005). Continuous nisin production in laboratory media and whey permeate by immobilized Lactococcus lactis. Process Biochem. 40:13-24.

Marsh EJ, Hongliang L, Hua W (2003). A three-tiered approach to differentiate Listeria monocytogenes biofilm-forming abilities. FEMS Microbiol. Lett. 228(2):203-210.

Meylheuc T, Renault M, Bellon- Fontaine MN (2006). Adsorption of a biosurfactant on surfaces to enhance the disinfection of surfaces contaminated with Listeria monocytogenes. Int. J. Food Microbiol. 109(1-2):71-78.

Mireles JRII, Adam T, Rasika MH (2001). Salmonella enterica serovar Typhimurium swarming mutants with altered biofilm-forming abilities: surfactin inhibits biofilm formation. J. Bacteriol. 183(20):5848-5854.

Moller S, Claus S, Jens BA, Bjarke BC, Juan LR., Michael G, Soren M (1998). In situ gene expression in mixed-culture biofilms: evidence of metabolic interactions between community members. Appl. Environ. Microbiol. 64(2):721-732.

Nicolella C, Mark CM, Sef JH (2000). Particle-based biofilm reactor technology. Trends Biotechnol. 18(7):312-320.

O'Brien J, lan W, Terry O (2000). Investigation of the Alamar Blue (resazurin) fluorescent dye for the assessment of mammalian cell cytotoxicity. Eur. J. Biochem. 267(17):5421-5426.

Okuno K, Tsuchiya K, Ano T, Shoda M (1993). Effect of super high magnetic field on the growth of Escherichia coli under various medium compositions and temperatures. J. Ferment. Bioeng. 75:103106

O'Toole G, Gibbs KA, Hager PW, Phibbs PV, Kolter R (2000). The global carbon metabolism regulator $\mathrm{Crc}$ is a component of a signal transduction pathway required for biofilm development by Pseudomonas aeruginosa. J. Bacteriol. 182(2):425-431.

O'Toole G, Kaplan HB, Kolter R (2000). Biofilm formation as microbial development. Ann. Rev. Microbiol. 54:49-79.

O'Toole G, Kolter R (1998). Initiation of biofilm formation in Pseudomonas fluorescens WCS365 proceeds via multiple, convergent signalling pathways: a genetic analysis." Mol. Microbiol. 28(3):449-461.

Otto K, Silhavy TJ (2002). Surface sensing and adhesion of Escherichia coli controlled by the Cpx-signaling pathway. Proc. Natl. Acad. Sci. USA 99(4):2287-2292.

Parkar SG, Flint SH, Brooks JD (2004). Evaluation of the effect of cleaning regimes on biofilms of thermophilic bacilli on stainless steel. J. Appl. Microbiol. 96(1):110-116.

Pitts B, Hamilton MA, Zelver N, Stewart PS (2003). A microtiter-plate screening method for biofilm disinfection and removal. J. Microbiol. Methods 54:269-276.

Pothakamury UR, Vega $\mathrm{H}$, Zhan, Q, Barbosa-Canovas GV, Swanson $B G$ (1996). Effect of growth rate and processing temperature on the inactivation of Escherichia coli by pulsed electrical fields. J. Food Prot. 59:1167-1171.

Potthoff A, Serve W, Macharts P (1997). The cleaning revolution. Dairy Ind. Int. 64(6):25-29.

Pratt LA, Kolter R (1998). Genetic analysis of Escherichia coli biofilm formation: roles of flagella, motility, chemotaxis and type I pili. Mol Microbiol. 30(2):285-293.
Qian Z, Sagers RD, Pitt WG (1997). The effect of ultrasonic frequency upon enhanced killing of Pseudomonas aeruginosa biofilms. Ann. Biomed. Eng. 25:69-76.

Qureshi N, Annous BA, Ezeji TC, Karcher P, Maddox IS (2005). Biofilm reactors for industrial bioconversion processes: employing potential of enhanced reaction rates. Microb. Cell Fact. 4:24.

Rodrigues L, Van der Mei H, Teixeira JA, Oliveira R (2004). Biosurfactant from Lactococcus lactis 53 inhibits microbial adhesion on silicone rubber." Appl. Microbiol. Biotechnol. 66(3):306-311.

Rogers J, Dowsett AB, Keevil CW (1995). A paint incorporating silver to control mixed biofilms containing Legionella pneumophila. J. Ind. Microbiol. 15(4):377-383.

Rosmaninho R, Nylander S, Paulsson OT, Muller SH, Melo L (2007). Modified stainless steel surfaces targeted to reduce fouling evaluation of fouling by milk components. J. Food Eng. 80:11761187.

Sauer K, Camper AK, Ahrlich GD, Costerton JW, Davies GD (2002). Pseudomonas aeruginosa displays multiple phenotypes during development as a biofilm. J. Bacteriol. 184(4):1140-1154.

Somers EB, Wong AC (2004). Efficacy of two cleaning and sanitizing combinations on Listeria monocytogenes biofilms formed at low temperature on a variety of materials in the presence of ready-to-eat meat residue. J. Food Prot. 67(10):2218-2229.

Spormann AM (2008). Physiology of microbes in biofilms. Curr. Top. Microbiol. Immunol. 322:17-36.

Stepanovic S, Cirkovic I, Ranin L, Stepanović S (2004). Biofilm formation by Salmonella spp. and Listeria monocytogenes on plastic surface. Lett. Appl. Microbiol 38(5):428-432.

Stewart GS, Williams P (1992). Lux genes and the applications of bacterial bioluminescence. J. Gen. Microbiol. 138(7):1289-1300.

Stewart PS (2003). Diffusion in biofilms. J. Bacteriol. 185(5):1485-1491.

Stewart, P. S. and Franklin M. J. (2008). Physiological heterogeneity in biofilms. Nat. Rev. Microbiol. 6(3):199-210.

Stickler DJ, Morris NS, Mclean RJ, Fuqua C (1998). Biofilms on indwelling urethral catheters produce quorum-sensing signal molecules in situ and in vitro. Appl. Environ. Microbiol. 64(9):34863490.

Suci PA, Mittelman MW, Yu FP, Geesey GG (1994). Investigation of ciprofloxacin penetration into Pseudomonas aeruginosa biofilms. Antimicrob. Agents Chemother. 38(9):2125-2133.

Todhanakasem T, Duangkamol K. and Ramida J. (2010). Reduced Formation and Elimination of Salmonella typhimurium Biofilm Using Crude Garlic Extract. KKU Res. J. 15(5):331-342.

Todhanakasem T, Young GM (2008). Loss of flagellum-based motility by Listeria monocytogenes results in formation of hyperbiofilms. J. Bacteriol. 190(17):6030-6034.

Watnick PI, Fullner KJ, Kolter R (1999). A role for the mannosesensitive hemagglutinin in biofilm formation by Vibrio cholerae El Tor. J. Bacteriol. 181(11):3606-3609.

Watnick PI, Kolter R (1999). Steps in the development of a Vibrio cholera El Tor biofilm. Mol. Microbiol. 34(3):586-595.

Wong AC (1998). Biofilms in food processing environments. J. Dairy Sci. 81(10):2765-2770. 